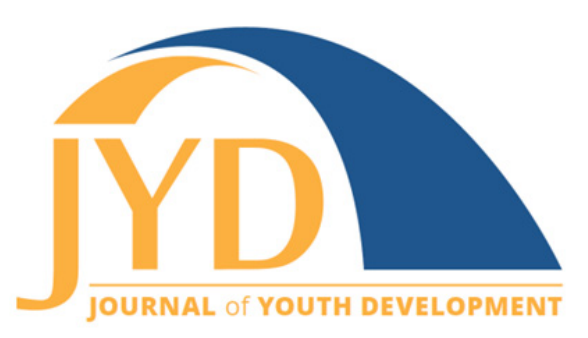

http://jyd.pitt.edu/ | Vol. 12 Issue 4 DOI 10.5195/jyd.2017.522 | ISSN 2325-4017 (online)

\title{
Supporting Adolescent Exploration and Commitment: Identity Formation, Thriving, and Positive Youth Development
}

\author{
Mary Elizabeth Arnold \\ Oregon State University \\ mary.arnold@oregonstate.edu
}

\begin{abstract}
The large body of literature on adolescent identity formation, pre-dating and found largely outside the main body of positive youth development (PYD) literature, shows that identity formation remains a key process for adolescent well-being. This paper revisits the critical adolescent task of identity formation proposed by Erikson (1950) and outlines an alignment of identity formation with adolescent thriving and PYD. By highlighting the congruency of identity formation and PYD the paper considers the role that youth development programs can play in assisting the process of identity formation in adolescents. Practical program implications for facilitating identity formation are presented.
\end{abstract}

Key words: identity formation, thriving, positive youth development, Erik Erikson

\section{Introduction}

The nature of human identity and how it is formed has been the subject of considerable research, discussion, and application since its entree into the scientific study of human development in the mid- $20^{\text {th }}$ century. Identity is reflected in a consistency of personhood, across situations, contexts and time (Erikson, 1968), presenting a coherent integration of one's self-understanding, goals, values, and behaviors that is constructed through the life choices one makes (Eichas, Meca, Montomery, \& Kurtines, 2015). Because of the physical, cognitive, social, and emotional changes that take place during the second decade of life, adolescence is the time when young people begin to question self-identity, and begin the process of answering the question of "who am I?", a question critical to lifelong pyscho-social wellbeing and thriving.

\footnotetext{
(c)) EY New articles in this journal are licensed under a Creative Commons Attribution 4.0 License. This journal is published by the University Library System, University of Pittsburgh and is cosponsored by the University of Pittsburgh Press. The Journal of Youth Development is the official peer-reviewed publication of the National Association of Extension 4-H Agents and the National AfterSchool Association.
} 


\section{Identity Formation, Thriving, and PYD}

Identity is often presented as something to achieve, as if one can place a confident checkmark next to that particular task, and move on in assured possession of self-definition. In reality, identity formation, which beings in earnest during adolescence, takes place across the lifespan in a continual cycle of confirmation and reappraisal (Côté \& Levine, 2016; Eichas et al., 2015).

According to Côté and Levine (2016), identity formation and self-development are parallel, but distinct aspects of human development. Identity formation is focused more on the stability of self over time, identified social roles, and arrangement of those social roles. Self-development is reflected in the perceptions of one's self within those roles. For example, an adolescent typically takes on the identity role of student, but his or her sense of competence in the student role is reflected in self-concept. To date, positive youth development (PYD) has largely considered development in terms of the self-awareness of the young person, rather than through the lens of identity. Take for example the prominent Five Cs model of PYD (Bowers et al., 2010) that measures confidence, competence, character, connection and caring through indices of youths' self-appraisal of the five constructs.

The aim of this paper is to elucidate the connections between identity formation, adolescent thriving, and PYD, and to explore related implications for youth development program practice. The goal of the paper is to broaden the youth development discourse through a renewed emphasis on the important developmental task of identity formation, a task that has lost prominence in the contemporary theories of PYD (Côté, 2011). It is important to note that multiple aspects of identity, such as social, religious, sexual, moral, cultural, and ethnic have been explored by developmental researchers. For the purpose of this paper, identity is considered broadly, encompassing multiple identity dimensions, and exploring the processes that assist a young person in defining who he or she is as a stable entity over time and context.

\section{Identity Formation in Adolescence: A Wedding of Classical and Contemporary} Theories

The topic of human identity dates to ancient times when philosophers first pondered the significance of being human (Côté \& Levine, 2016). Building on the ego psychology work of Sigmund Freud, Erik Erikson (1956) brought identity formation to the forefront of human development by highlighting identity formation as a necessary step in reaching healthy human maturity and potential. Identity as Erikson proposed it is a complex phenomenon shaped by three separate, but interacting, influences: (a) one's own psychological processes, (b) the 


\section{Identity Formation, Thriving, and PYD}

context in which one resides, and (c) one's physical characteristics that can either facilitate or impede development (Erikson, 1968). According to Erikson (1968), identity formation is necessary for a young person to experience "wholeness" and youth must "feel a progressive continuity between that which he has come to be during the long years of childhood and that which he promises to become in the anticipated future; between that which he conceives himself to be and that which he perceives others to see him and expect of him" (p. 87).

The interplay of these influences is consistent with inquiry in the field of applied developmental science (Lerner, Fischer, \& Weinberg, 2000), and elucidated in the relational developmental systems model of individual-context interaction, where an emphasis is placed on the mutuallydefining interactions between the developing young person and his or her environment (Lerner, Lerner, von Eye, Bowers, \& Lewin-Bizan, 2011). The relational developmental systems model lies at the heart of PYD theory and practice. The process of identity formation and PYD are strikingly similar; indeed, identity formation is often a desired outcome of PYD programs, but has only recently begun to be included specifically in program models (Eichas et al., 2015).

Identity formation in adolescence is rarely spoken of directly in the PYD field, although it is certainly implied in much of the body of work. However, as Côté (2011) states: "The scholars in the Positive Youth Development movement can indeed be seen as carrying on the tradition of humanistic pioneers like Erikson who believed in the positive psychological potentials that can be nurtured-or stilted-by environmental influences" (p. 1225-26). Indeed, Côté (2011) makes a direct and valid point that the PYD framework aligns well with Erikson's (1968) psychosocial development stages, despite the dismissal of Erikson's work as "passé (at best), or wrong (at worst)" (p. 1225).

Erickson's (1950) developmental theory asserts that all humans undergo the resolution of developmental "crises" as they grow from infancy to old age. Each crisis poses a developmental dilemma that individuals must resolve in a positive manner in order to progress through life successfully. As an infant, we must develop trust in the world around us; as toddlers we begin to develop autonomy; as young children we learn to take initiative and begin to exert some control over our lives; and as childhood draws to a close, we develop a sense of industry and accomplishment, often through social and academic success. According to Erikson (1950), the primary task of adolescence is the development of identity, the ability to know one's self, to develop stability in how one sees oneself, and to be true to that self, based on personal agency, which Erikson called fidelity. 


\section{Identity Formation, Thriving, and PYD}

Waterman (1984) described identity as having a clear sense of one's self, made up of goals, values and behaviors to which one is solidly committed, that provides purpose, direction and meaning to a young person's life. Waterman (1984) presents two possible drivers for the innate search for personal identity. The first is based on the discovery of one's true self. Implied in the notion of discovery is the idea that one's identity already exists-a predestination to be discovered. The discovery approach to identity has its roots in Aristotelian ethic that each human has a true self to discover, and that each person has an obligation to know his or her true self (Norton, 1976). Embodied in the discovery approach to identity, is the possibility of personal fulfillment, echoes of which are found in Maslow's (1968) description of "peak experiences," Csikszentmihalyi's (1990) concept of "flow," and Benson and Scales' (2011) description of "sparks" and their relationship to adolescent thriving.

The other driver for identity formation, according to Waterman (1984), is creation, implying that there is not one "true" self, but rather many possible selves that can be created through personal exploration, by trial and error, and supported or limited by the interaction with the context in which a young person develops. Indeed, exploration can be seen as the basic process that guides identity formation (Berman, Schwartz, Kurtines, \& Berman, 2001). The creation driver is seen in developmental models that emphasize the interplay between the young person, his or her innate capabilities and the mutual interactions between self and context. Echoes of the creation driver are evident in current relational developmental theory that emphasizes person-context interaction as the driver for PYD (Lerner et al., 2011).

A created identity is formed from a seemingly endless array of choices, with the implication that young people can become anything they want to be. Inherent in the creation approach, however, is the possibility of increased anxiety young people search for who they are. One of the identified dark sides of identity formation is anxiety that is produced for adolescents who worry about their ability to form an adequate identity (Alsaker \& Kroger, 2006). According to Waterman (1984), there is an inherent drive to create an identity as a way to avoid the fear of being undefined, and yet at the same time, there is also a fear of foreclosing on an identity that creates stasis or stagnation (Kensington, 1970). Although Waterman (1984) identified the two drivers of discovery and creation, he is careful to point out that they are not mutually exclusive, and that the parameters of one's "true" self are sufficiently broad that creation and discovery are not as distinct in the lived experiences of adolescents as they are in theory.

Contributions of other scholars have emphasized the continued role of exploration particularly through in-depth exploration and reconsideration of identity possibilities (Crocetti, Rubini, \& 
Identity Formation, Thriving, and PYD

Meeus, 2008; Meeus, 1996), supporting the premise that positive identity formation is progressive and evolving. This premise is supported through research that shows most youth tend to make initial commitments toward identity in early adolescence that are explored in increasingly more depth in middle to late adolescence (Klimstra, Hale, Raaijmakers, Branje, \& Meeus, 2010; Luyckx, Soenens, \& Goosens, 2006; Meeus, Iedema, Helsen, \& Vollebergh, 1999). Valde (1996) goes even further, arguing that once one has established an identity it is important to remain flexible in one's identity commitments. Those who do remain flexible score higher on self-actualization measures than those who hold on to rigidly held identities.

\section{Models of Adolescent Identity Formation}

One of the perennial critiques of identity formation is that it is not defined well enough to be tested empirically, and then, from such testing, translated into practical use (Coleman, 2011). Marcia's (1983) Identity Status theory is the most enduring operational model of identity formation, and the basis from which further models have evolved. Marcia (1983) conceptualized identity formation through the dimensions of exploration and commitment. Exploration is the process of looking for new roles, trying different ideas on, and opening up to new possible ideals, values, goals, and skills. Exploration is driven by the basic question of "is this me?" Commitment, on the other dimension is defined by choices and actions based on an emerging understanding of who one is. Commitments are typically made in terms of values, expectations, personal parameters, goals, and beliefs, as well as educational and vocational decisions. A key component of healthy identity commitments is that they are made based on one's own selfdefinition, and driven by emerging self-understanding, not on the expectations, values, or goals of others, such as parents, peers, or social organizations. Differentiating self from others, and acting on self-knowledge is critical to authentic identity formation (Coleman, 2011).

When the dimensions of exploration and commitment are juxtaposed, four quadrants representing Marcia's (1983) Identity Status model are formed: Diffusion, Foreclosure, Moratorium, and Achieved (see Figure 1).

According to Marcia (1983), adolescents who have not started identity formation are in the diffused state (low exploration, low commitment), having not committed to any identity, nor explored possibilities. Foreclosed adolescents (low exploration, high commitment) have formed an identity without exploring other available options. This is often illustrated by youth who commit to beliefs, values, and goals based on the opinions or expectations of others. Adolescents in the moratorium status (high exploration, low commitment) are actively seeking 


\section{Identity Formation, Thriving, and PYD}

out possibilities for self-identity, but have not yet made clear identity choices. Finally, adolescents in the achieved status (high exploration, high commitment) have established an identity that is self-determined and based on the individual's own beliefs, values, and gaols, often illustrated by choices of career path, social roles, and personal ideology.

Figure1. Identity Status Model (Marcia, 1983)

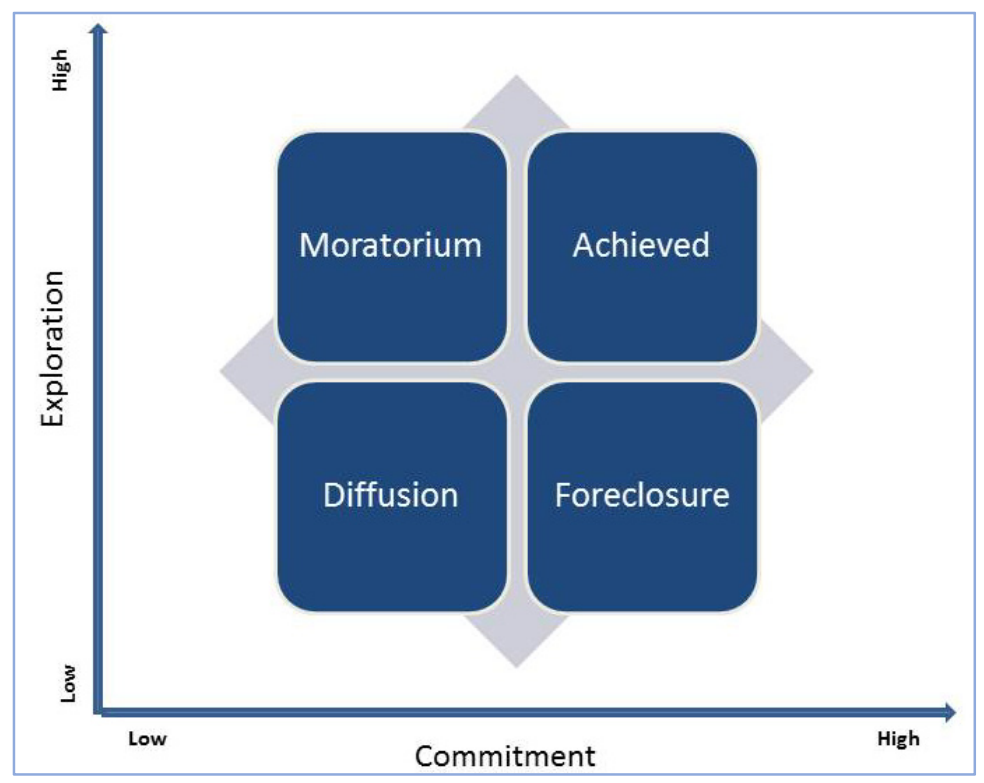

Subsequent research on the Marcia's theory has supported the four-status description, revealing characteristics of each status that are important to understanding trajectories of youth development and thriving, with important implications for youth programming (Alsaker \& Kroger, 2006; Coleman, 2011; Kroger, 2004). Adolescents who fall into the diffused identity status generally have higher levels of psycho-social problems, such as poor peer relations, low levels of self-esteem, and higher levels of hopelessness, and social isolation (Alsaker \& Kroger, 2006). Adolescents with a foreclosure identity status tend to be more authoritarian in nature, are more rigid in ideology, and are less open to new experiences (Côté \& Levine, 1983; Stephen, Fraser, \& Marcia, 1992). Foreclosed adolescents are less anxious, however, but this is interpreted as there "not being room" for anxiety when one is certain of who he or she is (Alsaker \& Kroger, 2006).

The influence of context on identity formation is also supported by Kroger, Martinussen, \& Marcia (2010), who found that youth coming from a "closed" or limited context, such as a small religious school, membership-only communities, or other systems of closed and closely held 
Identity Formation, Thriving, and PYD

beliefs and values had a higher proportion of foreclosed youth and less identity achievement during the transition to adulthood. Adolescents in the foreclosed and diffused identity statuses are marked by limited exploration of identity possibilities, and the results of this limitation have detrimental effects on the young person. This finding underscores again the importance of open educational, recreational and community contexts that offer a broad range of opportunities and support for identity exploration to support optimal identity development.

Alternatively, the moratorium and achieved identity statuses are both marked by high exploration, with more positive results. Adolescents in the identity-achieved status are typically psychologically healthier than adolescents in other identity statuses (Coleman, 2011). Likewise, emerging adults in moratorium and achieved status report more pro-social tendencies than those in identity diffusion (Padilla-Walker, Barry, Carroll, Madsen, \& Nelson, 2008).

Research on Marcia's model generally supports a progression from diffused to achieved status across adolescence (Kroger et al., 2010). However, the authors note that many youth had not reached achieved status by early adulthood, indicating that identity development continues beyond adolescence. This finding is consistent with recent theorists who propose that the road to adulthood, along with the traditional developmental markers of transitioning to adulthood, is delayed in contemporary society, and thus argue for a new developmental phase entitled "emerging adulthood" that is distinct from late adolescence and young adulthood (Arnett, 2004; Padilla-Walker et al., 2008).

Despite the usefulness of Marcia's (1983) theory for describing identity formation, it does not identify the processes through which formation takes place (Crocetti, 2017). Similarly, recent PYD literature has highlighted the increasing need to understand the processes through which youth development takes place (Arnold, 2015; Roth \& Brooks-Gunn, 2016). In an effort to understand the process of identity formation more clearly, Crocetti et al. (2008) proposed a dual-cycle model of identity formation and maintenance. Crocetti (2017) purports that identity formation is an interplay between commitment and reconsiderations that challenge previous commitments. Identity maintenance, on the other hand, is an interplay between commitment and in-depth exploration, the purpose of which is to validate the commitment, thus leading to its maintenance. Elucidating the processes through which identity is formed and maintained has important implications for youth development programs. 


\section{Identity Formation as PYD: A Return to Erikson}

In his eloquent commentary on the place of PYD within wider scholarly endeavors to understand human development, James Côté (2011) interpreted recent PYD research through the lens of Erikson's (1950) psycho-social developmental framework. Côté acknowledges just how far the field of adolescent development has come when he points out that recent PYD research "verifies many of the principles with which Erikson worked, with data and statistical methods that Erikson could not have imagined" (p. 1225). Côté also invites scholars to consider again-to read more carefully-Erikson's theory of development over the lifespan, and highlights several places where the constructs of PYD are evident in what Erikson wrote over 60 years ago.

Erikson's neo-psychoanalytic perspective on human development is my home court, the place where my own studies began, and I did not need to be asked twice to take on that careful rereading of Erikson's texts, now yellowed with age. Returning to these texts again was like finding an old friend, and becoming reacquainted after years of separation. In those intervening years I have been a practitioner scholar in the PYD field, following the developments of theory closely, and translating theory into practice in my work as a youth development specialist. I do not easily refer to myself as a developmental scientist however; rather, I am distinctly a developmental philosopher, one who ponders the discourses of developmental science, the well-worn paths from which new discoveries have emerged, and what they mean for practice in the world of youth development. The observations and understandings of human and, particularly in this case, adolescent development that Erikson put forth were not tested through hypotheses based on elegant and elaborate structural models. Nonetheless, what Erikson described in terms of healthy adolescent development matches the proposed definition of thriving put forth by Benson and Scales (2011), which is framed by PYD (Lerner et al., 2011).

Benson and Scales (2011) make a compelling case for thriving as a developmental process (Moshman, 2005), describing four unique qualities that set thriving apart from other contemporary theories of positive human development. First, thriving is rooted in the principles of developmental systems theory, which emphasizes development in an ecological context that is bi-directional and mutually beneficial. Second, thriving is essential pro-social, with an orientation toward, and responsibility for, helping others. Third, this pro-social sensibility is a direct outgrowth of finding and nurturing one's talents and passion. Finally, thriving has a distinctly spiritual emphasis that involves virtue and character strength. Thriving in adolescence is very similar to the successful development of personal identity, especially when both are 
Identity Formation, Thriving, and PYD

considered as a developmental process rather than statuses. Additionally, contribution to others and civic engagement are consistent outcomes of successful identity formation and adolescent thriving (Crocetti, 2017; Hershberg, Desouza, Warren, Lerner \& Lerner, 2014)

Corollaries of the four criteria of thriving are found throughout Erikson's works. Erikson's psycho-social developmental stages outlined a process of development, cumulatively dependent on the successful resolution of a series of eight "tasks" (Erikson, 1950). Consistent with developmental systems theory Erikson underscores the contextual and interactive nature of human development. Furthermore, the prosocial aspect of thriving also aligns with key aspects of Erikson's theory. The first task in infancy is to develop a basic trust in life, in one's environment, and in others. Erikson believed the development of trust sets the stage for the possibility of later pro-social drives (Browning, 1975). As a child progresses into early adolescence, and into the psycho-social task of identity formation proper, two qualitatively different pro-social constructs begin to emerge: morality and ideology (Wright, 1982; Xing, Chico, Lambouths, Brittian, \& Schwartz, 2015). Young adolescents are guided by the rules, norms and values presented to them by their parents and society. As adolescence progresses, however, the young person must begin to form an internalized personal ideology that is uniquely his or her own. Subsequent decisions are guided by the young person's fidelity to the emerging ideology. Erikson proposed that development of and fidelity to one's ideology in adolescence is the basis from which a young person can make responsible and ethical contributions as an adult (Wright, 1982). The ultimate contribution in adulthood is represented in Erikson's (1950) last psycho-social stage of generativity, a "universal sense of values assented to with insight and foresight in anticipation of immediate responsibilities not the least of which is the transmission of these values to the next generation" (Erikson, 1970, p. 164.). While Erikson positioned the stage of generativity late in the lifecycle, more indicative of middle to old age than youth, he also stated that such a pro-social adult sensibility has its genesis in the successful resolution of earlier developmental stages. Adolescent identity, developed through an exploration of one's self and interests, is the key factor that links early morality to later generativity (Wright, 1982).

Finally, the emphasis of thriving as a spiritual process is also found in Erikson's work, albeit in a slightly different form, indicative of the times in which Erikson wrote. Erikson considered at length the religious requirements and implications of human development (Wright, 1982), which reflect the social structures more prevalent 60 years ago that confined one's spiritual being to the institutions of religion. At the core of Erikson's understanding was that one's moral and ideological development is essentially a religious enterprise, an idea that was carried forward 
Identity Formation, Thriving, and PYD

into the realm of spiritual development by neo Eriksonian scholar Robert Coles (1991) as he realized that the moral actions and ideas of the children he studied could not be understood with any satisfaction unless considered through a religious or spiritual lens.

While usually understated in descriptions of PYD, spiritual development is often implicitly or explicitly part of many programs (Catalano, Berglund, Ryan, Lonczak \& Hawkins, 2002). Furthermore, the nature of spiritual development and its role in thriving, PYD, and identity formation represents a significant new thrust in the adolescent development literature (Benson, Roehlkepartain, \& Rude, 2003; Benson \& Roehlkepartain, 2008; MacDonald, 2011; Warren, Lerner \& Phelps, 2011).

\section{Identity Formation as Thriving: Implications for Positive Youth Development Programs}

This paper revisited the critical adolescent task of identity formation put forth by Erikson (1950) and explored an alignment of identity formation, adolescent thriving and PYD in an effort to bring identity formation more fully into the youth development practice discourse. This is not to propose that the three are synonymous, because indeed they are not. However, the extensive body of literature, pre-dating, and found largely outside the main body of PYD literature, shows that identity formation remains a key process for adolescent well-being (McClean \& Syed, 2015; Schwartz, Luyckx, \& Vignoles, 2011). Furthermore, identity formation is an inherent dimension of adolescent thriving as proposed centrally in the PYD literature, sharing all of the key characteristics for thriving outlined by Benson and Scales (2011).

Three aspects of identity formation specifically inform PYD programming. First, is the importance of supporting adolescent exploration of possible identities. The evidence provided in this paper supports the multiple ways that such exploration contributes to adolescent thriving, whether it is through supporting a young person's nascent discovery of his or her most driving passions, or providing multiple opportunities for youth to try on roles, and to learn through trial and error those things at which they excel. Key to the exploration is the underlying process of increase in personal agency, confidence, and, over time, commitment, to one's self-definition. This process is consistent with, and illustrated well by Benson and Scales (2011) in their proposal to support the identification and development of youth "sparks." 
Identity Formation, Thriving, and PYD

In practicality, individual adolescents will present a preference to explore personal identity development through discovery or creation, and attention should be paid toward understanding those adolescents who appear to resonate deeply with experiences that define who they are (Benson \& Scales, 2011; Coatsworth, Palen, Sharp, \& Ferrer-Wreder, 2006), and providing the contextual support, opportunities and encouragement to youth who are trudging through a jungle of possibilities on the path to identity formation (Jones \& Deutsch, 2012; Tanti, Stukas, Halloran, \& Foddy, 2011).

Dworkin, Larsen, \& Hansen (2003) highlight the importance of exploration in identity formation, particularly through the multiple activities in which youth participate. Such active participation allows youth to learn who they are by exploring what they enjoy, and learning what they are good at, as well as what they are not. By exploring possibilities in the context of typical adolescent activities, youth become agents of their own development through the intentional and purposeful trying on of possible selves. Dworkin et al. (2003) further emphasize the importance of a young person's willingness to engage in self-defining activities, and to stretch beyond one's comfort level in order to learn more about who one is.

The second key implication for youth programming is the recognition that identity formation is essentially developmental. As such, programs seeking to support identity development in youth must be thoughtfully structured in light of the developmental changes that take place from early to late adolescence. Programs for early adolescents may offer opportunities for identity exploration without any expectation for commitments toward identity. These explorations are conducted within programmatic contexts that support a young adolescent's need to belong; develop competence in basic skills; and navigate the basic moral structures, such as program rules and expectations; in order to form a secure foundation for the later ideological and identity commitment tasks. Likewise, programs for middle and late adolescents should focus on helping youth discover or create an expressive sense of self, with encouragement toward increasing identity commitment to support the transition to emerging adulthood. Similarly, Coatsworth et al. (2006) highlight the importance of youth discovering an "expressive identity," a discovery that often comes about through engagement with activities that become selfdefining for an adolescent.

A critical developmental aspect of PYD programs seeking to enhance identity formation is an increasing emphasis on the exploration of post-adolescent opportunities and pathways to those opportunities, which in turn help a young person find his or her way through a myriad of choices, thus reducing the potential for psychological distress. Goal-setting based on the young 


\section{Identity Formation, Thriving, and PYD}

person's emerging identity becomes an essential ingredient for programs at this stage. Along with this, however, is the explicit need to encourage late adolescents to reflect on their goals and plans to ensure that such ideas are coming from an internal sense of who the young person sees him or herself to be, and not on the expectations and desires of those external to the self. The internal nature of identity formation is critical in today's world that demands much of adolescents in order to "succeed" in life; demands to which adolescents may respond without appropriate reflection on how well they match their own emerging self-definition.

Finally, youth programs must support identity formation in ways that are consistent with the expectations of contemporary society, recognizing the multiple contexts in a young person's life and the influence of these contexts on identity formation. When Erikson originally proposed identity development, the adolescent world was much more predictable and structured. Change, at least compared to the pace we witness today, was slower, and social roles, which informed many identities, were more defined. As such, the traditional concept of identity formation had a more static quality, as reflected in Marcia's final status of "identity achieved." In today's postmodern world, little is static, homogenous, or definitively structured, as such, adolescent identities need to be viewed as fluid and adaptable across the life span (Côté \& Levine, 2016). Furthermore, the identification of the emerging adulthood years as a distinct phase between adolescence and young adulthood has considerable implication for the nature and timing of identity formation.

By intentionally including identity formation in programs for adolescents, PYD practitioners can play an important role in delivering adolescents to the edge of adulthood with sufficient fidelity to self-definition and personal ideology to navigate an increasingly complex social milieu. Indeed, if we consider the relevancy of Erikson's theory for contemporary adolescent development and its alignment with thriving and PYD, identity formation is arguably the most important outcome for youth programs across the adolescent years.

\section{References}

Alsaker, F., \& Kroger, J. (2006). Self-concept, self-esteem, and identity. In S. Jackson \& L. Goossens (Eds.), Handbook of adolescent development (pp. 90-113). New York: Psychology Press.

Arnett, J. J. (2004). Emerging adulthood: The winding road from the late teens through the twenties. New York: Oxford University Press.

Arnold, M. E. (2015). Connecting the dots: Improving Extension program planning with program umbrella models. Journal of Human Sciences and Extension, 3(2) 48-67. 
Journal of Youth Development | http://jyd.pitt.edu/ | Vol. 12 Issue 4 DOI 10.5195/jyd.2017.522

\section{Identity Formation, Thriving, and PYD}

Benson, P. L., Roehlkepartain, E. C. (2008). Spiritual development: A missing priority in youth development. New Directions for Student Leadership, 2008(118), 13-28.

Benson, P. L., Roehlkepartain, E. C., \& Rude, S. P. (2003). Spiritual development in childhood and adolescence: Toward a field of inquiry. Applied developmental science, 73), 205-213.

Benson, P. L., \& Scales, P. C. (2011). Thriving and sparks. In R. J. R Leveque (Ed.), Encyclopedia of Adolescence (pp. 2963-2976). New York: Springer.

Berman, A. M., Schwartz, S. J., Kurtines, W. M., \& Berman, S. L. (2001). Journal of Adolescence, 24, 513528.

Bowers, E. P., Li, Y., Kiely, M. L., Brittian, A., Lerner, J. V., \& Lerner, R. M. (2010). The five Cs model of positive youth development: A longitudinal analysis of confirmatory factor structure and measurement invariance. Journal of Youth and Adolescence, 39(7), 720-735.

Browning, D. S. (1975). Generative man: Psychoanalytic perspectives. New York: Dell.

Catalano, F., Berglund, M. L., Ryan J. A. M., Lonczak, H. S., Hawkins, J. D., (2002). Positive youth development in the United States: Research findings on evaluations of positive youth development programs. Prevention \& Treatment, 5, 1-111. Retreieved from http://aspe.hhs.gov/hsp/positiveyouthdev99/

Coatsworth, J. D., Palen, L., \& Sharp, E. H., (2006). Self-defining activities, expressive identity, and adolescent wellness. Applied Developmental Science, 10(3), 157-170.

Coles, R. (1991). The spiritual lives of children. New York: Houghton Mifflin.

Coleman, J. C. (2011). The nature of adolescence ( $4^{\text {th }}$ ed.). New York: Routledge.

Côté, J. E. (2011). The place of the positive youth development perspective within the larger project of mapping human development: Invited commentary. Journal of Adolescence, 34, 1225-1227.

Côté, J. E., \& Levine, C. (1983). Marcia and Erikson: The relationship among ego identity status, neuroticism, dogmatism, and purpose in life. Journal of Youth and Adolescence, 12(1), $45-53$.

Côté, J. E., \& Levine, C. (2016). Identity formation, youth and development: A simplified approach. New York: Psychology Press

Crocetti, E. (2017). Identity formation in adolescence: The dynamic of forming and consolidating identity commitments. Child Development Perspectives, 11(2), 145-150.

Crocetti, E., Rubini, M., \& Meeus, W. (2008). Capturing the dynamics of identity formation in various ethnic groups: Development and validation of a three-dimensional model. Journal of Adolescence, 31(2), 207-228.

Csikszentmihalyi, M. (1990). Flow: The psychology of optimal experience. New York: Harper-Collins.

Dworkin, J.B., Larson, R., \& Hansen, D. (2003). Adolescents' accounts of growth experiences in youth activities. Journal of Youth and Adolescences, 32(1), 17-26. 
Journal of Youth Development | http://jyd.pitt.edu/ | Vol. 12 Issue 4 DOI 10.5195/jyd.2017.522 Identity Formation, Thriving, and PYD

Eichas, K., Meca, A., Montgomery, M. J., \& Kurtines, W. (2015). Identity and positive youth development: Advances in developmental intervention science. In K. C. McClean \& M. Syed (Eds.), The Oxford Handbook of Identity Development (pp. 337-354). New York: Oxford University Press.

Erikson, E. H. (1950). Childhood and society. New York: Norton.

Erikson, E. H. (1956). The problem of ego identity. Journal of the American Psychoanalytic Association, 4, 56-121.

Erikson, E. H. (1968). Identity, youth and crisis. New York: Norton.

Erikson, E. H. (1970). Reflections on the dissent of contemporary youth. Daedalus, 99(1), 154-176.

Herschberg, R. M., DeSouza, L. M., Warren, A. E. A., Lerner, J. V., \& Lerner, R. M. (2014). Illuminating trajectories of adolescent thriving and contribution through the words of youth: Qualitative findings form the 4-H Study of Positive Youth Development. Journal of Youth and Adolescence, 43, 950-970.

Jones, J. N., \& Deutsch (2012). Social and identity development in an after-school program: Changing experiences and shifting adolescent needs. Journal of Early Adolescence, 33(1), 17-43.

Kensington, K. (1970). Youth and dissent. New York: Harcourt, Brace, \& Jovanovich.

Klimstra, T. A., Hale, W. W., III, Raaijmakers, Q. A. W., Branje, S. J. T., \& Meeus, W. H. J. (2010). Identity formation in adolescence: Change or stability? Journal of Youth and Adolescence, 39, 150-162.

Kroger, J. (2004). Identity in adolescence: The balance between self and other. ( ${ }^{\text {rd }}$ ed.). New York: Routledge.

Kroger, J., Martinussen, M., \& Marcia, J. E. (2010). Identity status change during adolescence and young adulthood: A meta analysis. Journal of Adolescence, 33, 683-698.

Lerner, R. M., Fisher, C. B., \& Weinberg, R. A. (2000).Toward a science for and of the people: Promoting civil society through the application of developmental science. Child Development, 71(1), 11-20.

Lerner, R. M., Lerner, J. V., von Eye, A., Bowers, E. P., \& Lewin-Bizan, S. (2011). Individual and contextual bases of thriving in adolescence: A view of the issues. Journal of Adolescence, 34, 1107-1114.

Luyckx, K., Soenens, B., \& Goosens, L. (2006). The personality-identity interplay in emerging adult women: Convergent findings from complementary analyses. European Journal of Personality, 20, 195-215.

MacDonald, D. A. (2011). Spiritual identity: Individual perspectives. In S. J. Schwartz, K. Luyckx, \& V. L. Vignoles (Eds.), Handbook of identity theory and research (Volume 2). (pp. 531-544). New York: Springer.

Marica, J. E. (1983). Some directions for the investigation of ego development in early adolescence. Journal of Early Adolescence, 3, 215-223.

Maslow, A. H. (1968). Toward a psychology of being. Princeton, NJ: Van Nostrand. 
Journal of Youth Development | http://jyd.pitt.edu/ | Vol. 12 Issue 4 DOI 10.5195/jyd.2017.522

Identity Formation, Thriving, and PYD

McClean, K. C., \& Syed, M. (Eds.). (2015). The Oxford handbook of identity development. New York: Oxford University Press.

Meeus, W. (1996). Studies on identity development in adolescence: An overview of research and some new data. Journal of Youth and Adolescence, 25(5), 569-598.

Meeus, W. H. J., Iedema, J., Helsen, M., \& Vollebergh, W. (1999). Patterns of adolescent identity development: Review of literature and longitudinal analysis. Developmental Review, 19, 419-461.

Moshman, D. (2005). Adolescent psychological development: Rationality, morality, and identity. (2nd ed.). Mahwah, NJ: Lawrence Erlbaum.

Norton, D. L. (1976). Personal destinies: A philosophy of ethical individualism. Princeton, NJ: Van Nostrand.

Padilla-Walker, L. M., Barry, C. M., Carroll, J. S., Madsen, S. D., \& Nelson, L. J. (2008). Looking on the bright side: The role of identity status and gender on positive orientations during emerging adulthood. Journal of Adolescence, 31, 451-467.

Roth, J. L., \& Brooks-Gunn, J. (2016). Evaluating youth development programs: Progress and promise. Applied Developmental Science, 20 (3), 188-202.

Schwartz, S. J., Luyckx, K., \& Vignoles, V. L. (Eds.). (2011). Handbook of identity theory and research (Vol. 1). New York: Springer.

Stephen, J., Fraser, E., \& Marcia, J. E. (1992). Moratorium-achievement (mama) cycles in lifespan identity development: Values orientations and reasoning system correlates. Journal of Adolescence, 15, 283-300.

Tanti, C., Stukas, A. A., Halloran, M. J., Foddy, M. (2011). Socarnoldial identity change: Shifts in social identity during adolescence. Journal of Adolescence, 34, 555-567.

Valde, G. A. (1996). Identity closure: A fifth identity status. Journal of Genetic Psychology, 1573), 245254.

Warren, A. E., Lerner, R. M., \& Phelps (Ed.s), (2011). Thriving and spirituality among youth: Research perspectives and future possibilities. New York: Wiley.

Waterman, A. S. (1984). Identity formation: Discovery or creation? Journal of Early Adolescence, 4, 329341.

Wright, J. E. (1982). Erikson: Identity and religion. New York: Seabury Press.

Xing, K., Chico, E., Lambouths, D. L., Brittian, A. S., \& Schwartz, S. J. (2015). Identity development in adolescence: Implications for youth policy and practice. In E. P. Bowers, G. J. Geldhof, S. K. Johnson, Hilliard, L. J., Hershberg, R. M., J. V. Lerner, \& R. M. Lerner (Eds.), Promoting positive youth development: Lessons from the 4-H study (pp. 187-208). New York: Springer. 